\title{
O PAPEL DA CONTROLADORIA NO SUPORTE AO PROCESSO DE GERAÇÃO DE INFORMAÇÕES VOLTADAS AO CONTROLE DE GESTÃO OPERACIONAL EM UMA ORGANIZAÇÃO DO TERCEIRO SETOR
}

Letícia Melo De Lima ${ }^{1}$

Maria Margarete Brizolla ${ }^{1}$

${ }^{1}$ Universidade Regional do Noroeste do Estado do Rio Grande do Sul 


\title{
O PAPEL DA CONTROLADORIA NO SUPORTE AO PROCESSO DE GERAÇÃO DE INFORMAÇÕES VOLTADAS AO CONTROLE DE GESTÃO OPERACIONAL EM UMA ORGANIZAÇÃO DO TERCEIRO SETOR
}

\author{
Letícia Melo de Lima ${ }^{1}$ \\ Maria Margarete Baccin Brizolla ${ }^{2}$
}

\section{RESUMO}

A controladoria tem por finalidade garantir informações adequadas ao processo decisório dos gestores, planejando, controlando, definindo modelos de decisões que auxiliem na gestão da organização. O objetivo do presente estudo consiste em verificar como a controladoria pode dar suporte ao processo de geração de informações voltadas ao controle de gestão operacional em uma entidade sem fins lucrativos. A metodologia utilizada quanto ao problema foi a qualitativa, utilizando o estudo de caso para analisar o sistema de informação, as políticas para elaboração do planejamento, os tipos de controles operacionais e indicadores de desempenho para avaliação e acompanhamento das operações em uma entidade sem fins lucrativos. Os dados foram obtidos através de entrevistas semiestruturada realizadas com os gestores responsáveis, observação e ainda a análise documental. Os resultados indicam que a estrutura de controladoria encontrada na organização dá o devido suporte ao processo de geração de informações, a fim de ser um instrumento de gestão, contribuindo com o planejamento, execução e controle de suas atividades, auxiliando na tomada de decisões. De forma geral a organização possui instrumentos de gestão que podem levar a otimização dos resultados, apresentando uma gestão eficaz com gestores capacitados, gerando informações que possam ajudar no processo de tomada de decisões.

Palavras-chave: Contabilidade, Controle, Sistema de Informações, Gestão.

\section{INTRODUÇÃO}

A Contabilidade se define como um conjunto ordenado de conhecimentos próprios, leis, princípios e métodos de evidenciação próprios, ou seja, é a ciência que estuda, controla e observa o patrimônio de uma entidade em seus aspectos quantitativo (monetário) e qualitativo (físico). Dessa forma a gestão das entidades é um processo complexo e amplo, que necessita de uma adequada estrutura de informações. $O$ processo de gestão serve como suporte ao processo da tomada de decisões, realizando-se por meio de planejamento estratégico e operacional, programação, execução e controle (BERGONSO; SILVA, 2010).

Portanto, os sistemas de informações das empresas devem ser estruturados de forma a suprir as necessidades do processo de gestão durante as suas fases de planejamento, controle e execução. Assim entende-se que o sistema de informações é um conjunto integrado de informações, onde seu propósito consiste em apoiar as operações e funções de gestão de uma empresa e ainda propiciar uma análise de situações que o cercam, demonstrando informações precisas, relevantes e confiáveis e que estejam disponíveis aos seus gestores no formato e
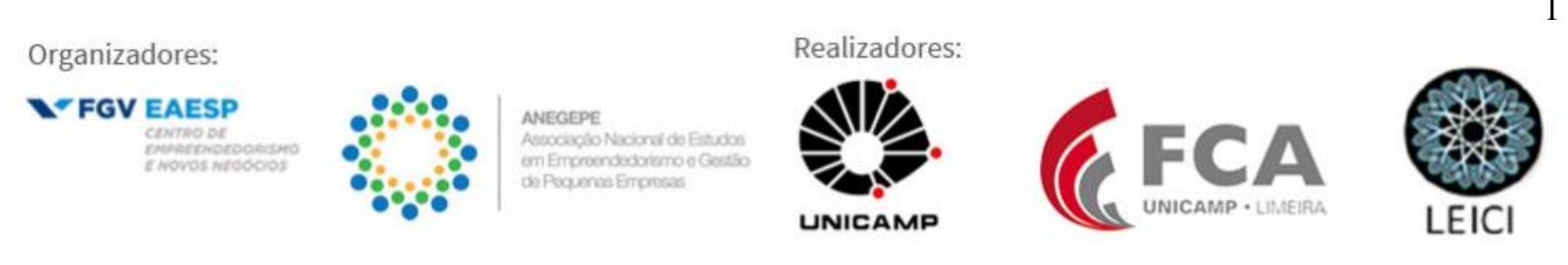
tempo adequado (NASCIMENTO; REGINATO, 2009; BASSO; BRIZOLLA; FILIPIN, 2017).

É de se notar que a controladoria, na estrutura da organização, conquistou posto magno, dado ser ela, ferramenta de ação que melhor instrui o gestor na avaliação das informações necessárias à definição do planejamento da empresa. A controladoria não está relacionada somente aos sistemas contábeis, ou seja, ela faz parte de todo o processo de gestão, desde o planejamento até o controle, oferecendo informações necessárias para o comprimento de suas ações. Assessorando a administração na busca de melhores resultados e ainda na otimização do resultado econômico da empresa. Dessa forma o processo de gestão deve ser subsidiado pela controladoria, órgão responsável pelo apoio e geração de informações confiáveis aos gestores em todas as etapas do processo de tomada de decisão (BERGONSO; SILVA, 2010).

O sistema de informações é o principal instrumento desse processo, captando ocorrências externas e internas e apoiando a empresa no processo de tomada de decisão. A controladoria responsabiliza-se pela execução e coordenação do que foi estabelecido junto aos gestores, assessorando e promovendo ações e tomadas de decisões para controlar e motivar as áreas que estão sob sua responsabilidade e acompanhar os gestores na elaboração dos planos e definições de padrões. Assim, a estruturação da controladoria, no exercício de acompanhamento das atividades da empresa, deve servir de instrumento na busca de informações gerenciais e estratégicas a fim de que os gestores possam tomar medidas corretivas no sentido de melhorar o processo de gerenciamento da empresa (DIAS, 2002; OLIVEIRA, 2009).

No atual contexto, as pequenas empresas têm dificuldade quanto a sua consolidação e manutenção no mercado e fecham as portas, em sua maioria, antes mesmo de completarem o segundo ano de vida, devido à ausência de informações, decisões tomadas de forma subjetiva gerando falhas gerenciais, e consequentemente o fechamento destas. Diante do impasse da necessidade de elaboração de gerenciamentos de forma eficaz e a ausência de conhecimento por parte dos gestores de como fazê-la, faz-se necessário a implementação da controladoria. Então a partir disso, evidenciar a importância, os benefícios e melhorias trazidas pela implantação da mesma como ferramenta de gestão e melhoria no processo gerencial e de tomada de decisão nas empresas de pequeno porte (BAIRRO, 2008).

Sendo assim, para cumprir sua missão, a área da controladoria precisa desempenhar um papel atuante nas diferentes etapas do processo de gestão. Afinal o processo decisório é influenciado pela atuação da controladoria por meio de informações de planejamento e controle. Pode-se dizer com isso, que a controladoria tem como finalidade buscar a adaptação do processo de gestão à realidade da organização perante seu meio ambiente de atuação (CREPALDI, 2015; SEBRAE, 2016). Diante deste contexto surge o seguinte problema: Como a controladoria pode dar suporte ao processo de geração de informações voltadas à controladoria, em uma entidade sem fins lucrativos? Para dar resposta a questão de pesquisa proposta o objetivo é identificar como a controladoria pode dar suporte ao processo de geração de informações voltadas à controladoria, em uma entidade sem fins lucrativos.

Os autores Bergonso e Silva (2010) realizaram um estudo que demonstrou a importância da controladoria como uma ferramenta para o processo de gestão, evidenciando e reunindo as informações gerenciais nas tomadas de decisões e assegurando a continuidade da

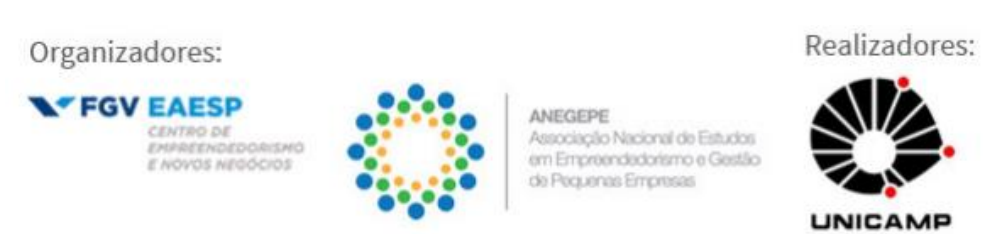

UNICAMP
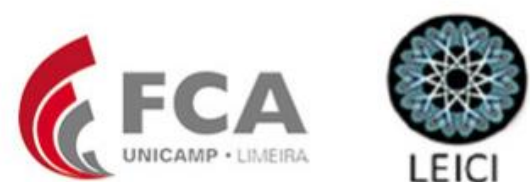
empresa com qualidade e competitividade. Seguindo na mesma expectativa, Beuren e Muller (2010) investigaram a estrutura formal e práticas da controladoria de suporte ao processo de gestão em empresas familiares brasileiras.

Bezerra e Lemos (2013), realizaram outro estudo que tinha como base a controladoria como ferramenta estratégica na melhoria da gestão de pequenas empresas. Cujo tema abordava questões ligadas à importância dessas empresas para a economia do país e os fatores de insucesso que contribuem para a sua mortalidade precoce. Assim objetivo geral era demonstrar a aplicação da controladoria como ferramenta estratégica na melhoria da gestão de pequenas empresas. Nesse sentido o presente estudo busca como diferencial demonstrar que a controladoria é considerada como um dos principais meios administrativos dentro de uma organização. Ela é a ferramenta que transmite aos gestores informações de recursos, análises de desempenho, para que se chegue ao objetivo final com eficiência e eficácia, assegurando assim, a otimização do resultado global da empresa.

\section{BASE CONCEITUAL}

O estudo apresenta inicialmente conceitos com relação à contabilidade, processos de gestão, controladoria, gestão de controles, expondo ainda os principais meios de controles existentes em uma entidade de pequeno porte.

\subsection{CONTROLADORIA E SISTEMA DE INFORMAÇÃO}

A controladoria como órgão administrativo zela pelo bom desempenho da empresa, desenvolvendo sistemas e metodologias que proponham modelos gerenciais que otimizem o desempenho das empresas por meio de seu sistema de gestão, fornecendo informações para os gestores que auxiliam na tomada de decisões. $\mathrm{O}$ órgão administrativo controladoria tem por finalidade garantir informações adequadas ao processo decisório, colaborando com os gestores na busca da eficácia gerencial. Controlar é uma área coordenadora das informações sobre gestão econômica, no entanto, ela não substitui a responsabilidade dos gestores por seus resultados obtidos, mas busca induzi-los à otimização do resultado econômico (NASCIMENTO; REGINATO, 2009; CREPALDI, 2015).

De acordo com Padoveze (2009, p. 3) “A controladoria pode ser definida, então, como a unidade administrativa responsável pela utilização de todo o conjunto da Ciência Contábil dentro da empresa".

Dessa forma a controladoria tem por sua finalidade garantir as informações adequadas ao processo decisório, que consiste em um corpo de doutrinas e conhecimentos relativos a gestão econômica. Assim como órgão administrativo com missão, funções e princípios, definidos no modelo de gestão da empresa; e como área de do conhecimento humano com fundamentos, conceitos, princípios e métodos originados de outras ciências (FISCH; MOSIMANN, 1999).

O sistema de informações pode ser conceituado como uma rede de informações, de fluxos que alimentam o processo da tomada de decisões. Esses sistemas permitem à empresa tornar o processo de tomada de decisão mais rápido, disponibilizando as informações em tempo real para que os gestores tomem decisões mais acertadas e com mais precisão. Onde os 
mesmos coletam, processam, analisam informações a partir de um objetivo, desse modo incluem-se entradas, processamentos e saídas de informações (ALVES; BONFIM; SOUZA, 2016).

As estruturas dos sistemas de informações possuem sistemas de simulação, que preveem os reflexos das alterações ambientais sobre os resultados estimados e ainda dos sistemas de padrões que permitem acompanhar o desempenho das atividades desenvolvidas. Esses sistemas interagem as informações do ambiente externo com o interno ligando as informações de uma área com a de toda a empresa, contribuindo com a elaboração do processo de gestão. Dessa forma os sistemas têm como função fornecer informações aos gestores, para que haja programação das atividades a serem desenvolvidas pela organização e assim obter um melhor controle das mesmas e dos resultados da organização (DIAS, 2002).

A atuação da área de controladoria pode ser vista sob duas perspectivas: primeira, como um órgão facilitador que fornece informações às demais áreas da empresa para que possam implementar suas estratégias específicas; segunda, como a área que procura integrar o processo de decisões estratégicas de cada área com o objetivo global da organização, ou seja, com a diretriz estratégica da empresa como um todo (PADOVEZE, 2009).

A implementação de um adequado sistema de informações permite à controladoria atuar no monitoramento e na integração do processo de gestão da organização, estruturado nas fases do planejamento estratégico e operacional, execução e controle. Essa integração é o nível de coesão segundo o qual decisões são tomadas pelas áreas, levando em conta o seu próprio resultado, sem, entretanto, dissociar-se dos objetivos globais da organização (DIAS, 2002; ALVES; BONFIM; SOUZA, 2016).

A partir do instante em que a controladoria assume o banco de dados e informações da organização, ela se responsabiliza pela qualidade das informações que serão repassadas aos gestores e demais interessados. Dessa forma a controladoria se insere no contexto organizacional como um órgão de linha ou staff, ou ainda como unidade administrativa. Que iniciará seu trabalho criando e implementando um sistema integrado de informações decisórias. Por conseguinte, as decisões que estão relacionadas à estrutura organizacional, ao nível de conhecimento dos subordinados e ao tipo de sistema de informações adotado pela empresa (DIAS, 2002; PADOVEZE, 2009).

\subsection{CONTROLADORIA NO SUPORTE A DECISÃO EM PEQUENAS EMPRESAS}

Anualmente surgem milhares de novas empresas no mercado brasileiro, estimulados pela descoberta de novas demandas e pelo intuito empreendedor dos brasileiros. A sobrevivência dessas empresas se deve a alguns fatores como a situação antes da abertura (experiência no ramo, motivação para abrir o negócio), o planejamento, gestão estratégica e ainda a capacitação dos empresários/gestores para administrar a empresa (FERNANDES; GALVÃO, 2016).

A controladoria, enquanto área responsável por abastecer as necessidades informativas dos gestores de uma empresa, precisa fazer uso de uma metodologia de controle e planejamento que permita desenvolver esta atividade de forma mais dinâmica e econômica possível, visto que, as organizações se encontram cada vez mais em um ambiente dinâmico, competitivo e complexo. Dessa forma para conseguirem progredir é necessário que as
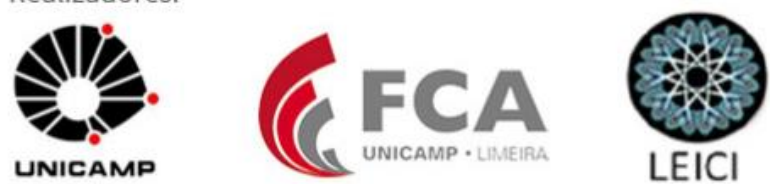
empresas possuam um procedimento de gestão estruturado na forma do ciclo planejamento, execução e controle (OLIVEIRA, 2009; PADOVEZE, 2009).

A necessidade de geração de informação de forma consistente e precisa para a tomada de decisão nas empresas é um dos grandes fatores para que a controladoria começasse a ganhar espaço no meio empresarial. Ela traz uma visão ampliada do negócio para os empresários, os muni com informações relevantes para definição das estratégias com o intuito de tornar a corporação cada vez mais competitiva e geradora de bons resultados. Podendo assim otimizar econômicos da empresa por meio de um sistema de informações baseado num modelo de gestão, onde as pequenas empresas possam se manter estruturalmente enquanto mercado econômico, administrativo e de gestão (MACHADO, L.; MACHADO, M.; SANTOS, 2008).

Portanto, no contexto das micro e pequenas empresas, a controladoria pode ser útil e de muita importância ao ser introduzida na cultura organizacional da organização e, junto com a missão de ser eficaz no modelo de gestão adequado, estabelecerá o modo como a empresa deverá ser dirigida. Logo, com suas funções determinadas e interligadas a um grupo de dados e objetivos adequados, quando atingidos, viabilizam o processo de gestão econômica, controlando os resultados do desempenho da empresa (MACHADO, L.; MACHADO, M.; SANTOS, 2008; BERGONSO; SILVA, 2010).

\subsection{ESTUDOS ANTERIORES}

O processo de controladoria atualmente nas organizações é tão importante e útil, que vários estudos já foram realizados na área ao longo dos anos, a fim de trazerem maiores informações e ferramentas para a gestão das organizações. Diversos autores realizam estudos, a grande maioria com relação aos controles e o processo de gestão com base na controladoria, a qual tem a função de controlar, planejar, avaliar os resultados e ainda elaborar e interpretar as informações da empresa.

Imoniana (2006) analisou a viabilidade de um modelo de gestão em organizações de serviços: um estudo comparativo de ações reativas, pró-ativas e filosofias coativas. O objetivo principal deste estudo foi comparar e contrastar as três filosofias de modelos de controle de gestão utilizados no processo de tomada de decisão, a saber, reativo, proativo e coativo. Dessa forma realizou-se um levantamento de 20 organizações de serviços para fazer uma análise mais abrangente. Para fazer isso, foram tomadas as seguintes etapas: primeiro, os fundamentos de modelos reativos, proativos e coativos foram destacados; em segundo lugar, comportamentos de gestão nas três abordagens foram comparados, com conceitos e práticas as aplicações foram destacadas, assim informações foram coletadas sobre as relações gerenciais na organizações. Os resultados mostraram a necessidade de uma mudança em paradigmas de gestão para que as empresas não sejam apenas comparadas através de recursos financeiros, perspectivas, sem considerar a análise dos modelos de controle de gestão que, como mostrado pelas descobertas deste estudo, influenciam diretamente os resultados operacionais das organizações.

Os autores Machado L., Machado M. e Santos (2008) investigaram a aderência das funções da controladoria em uma organização de médio porte. A organização investigada passou a adotar a controladoria com o objetivo de melhorar o sistema de informação para
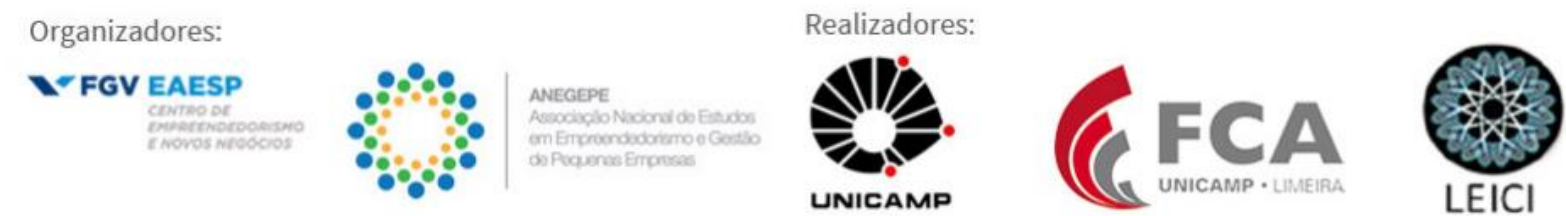
decisão, sendo este serviço terceirizado a uma empresa de consultoria e assessoria, fato inovador sob o ponto de vista de tomada de decisão. Assim o estudo teve por objetivo estudar se numa empresa que adota a controladoria ocorre à prática das principias funções da área, prevista nas obras consagradas sobre o tema, verificando a aderência dessas funções à atividade técnico-operacional da entidade pesquisada. Dessa forma percebeu-se a inconsistência entre as funções exercidas na empresa pela área de controladoria, concluiu-se que a controladoria foi criada sem definição de elementos-chave como missão e função, e as funções exercidas pela controladoria não guardam relações diretas com aquelas previstas.

O objetivo da pesquisa de Lunkes et. al (2009) foi identificar as funções da controladoria em manuais e obras de referências dos Estados Unidos, Alemanha e Brasil. Através de uma pesquisa bibliográfica e documental em obras da área chegou-se a conclusão que no Brasil 100\% dos livros citam que e função da controladoria é o planejamento. A opinião dos autores dos Estados Unidos e da Alemanha é de $80 \%$. Em relação a função controle, na Alemanha é de 100\% dos autores, no Brasil 80\% e nos Estados Unidos 70\% , isso acarretou a conclusão de que a preocupação principal dos integrantes da controladoria é o futuro das organizações.

Os autores Freitas e Lunkes (2011) também realizaram uma pesquisa a fim de identificar os aspectos organizacionais e comportamentos do controller e contador na gestão e tomada de decisões na organização. Os resultados indicaram que o controlle tem um baixo envolvimento no processo de tomada de decisão, se baseando nas análises da perspectiva de fatores organizacionais. Quanto aos fatores de comportamento, os resultados indicaram que o pensamento estratégico, habilidades de informática e a capacidade de lidar com a mudança e trabalhar em equipe, são habilidades importantes pelo envolvimento do controlador na tomada de decisões.

O estudo de Politelo et. al (2014) realizado no estado de Santa Catarina buscou verificar a estruturação da controladoria em uma empresa privada e em uma empresa sem fins lucrativos. Por meio de entrevistas com os responsáveis das áreas da controladoria das duas empresas do estudo, foi concluído que há entendimento semelhante quanto a função da controladoria dentro dessas organizações, sendo principalmente a área responsável pela gestão da informação.

Boniatti et al. (2015) verificaram como os fatores contingenciais influenciam na estrutura da controladoria de uma Instituição de Ensino Superior comunitária no Estado do RS. Constatou-se que o ambiente da instituição, do qual faz parte, é orgânico, com mudanças quando necessárias. A tecnologia faz parte do todo institucional, que ocorre centralização da decisão em relação à variável estrutura e que a estratégia está presente e é de extrema importância para a instituição. Além disso, os entrevistados elencaram que há reconhecimento da unidade através das atividades que executam, com pessoas capacitadas e relatórios em tempo hábil. Ainda, destacou-se a importância da busca pela qualificação e oportunidade em relação ao aprendizado de língua estrangeira.

Outro estudo realizado foi pela autora Crepaldi (2015), num Sindicato dos Contabilistas de Criciúma/SC, que teve como foco principal os controles de gestão, que são uma importante ferramenta para certificar que as operações estão sendo realizadas conforme o rumo pré-estabelecido, garantindo a continuidade da empresa. Assim, o objetivo geral desse estudo consistiu em verificar se os contadores filiados ao Sindicato dos Contabilistas do
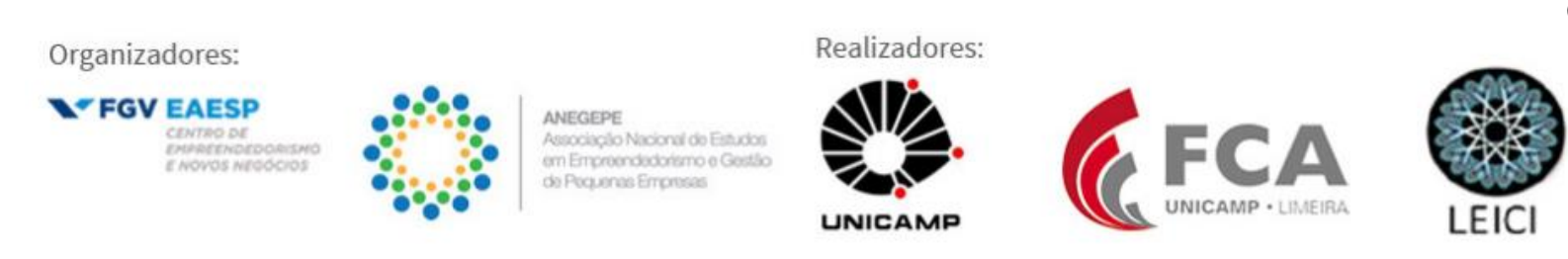
município de Criciúma atuavam na área gerencial por meio dos controles de gestão. Todavia os instrumentos de controle de gestão utilizados pelos contadores sejam eles, instrumentos contábeis gerenciais e demais instrumentos de auxílio à gestão, contatou-se ainda que maioria entende como nível de contribuição forte, as demonstrações contábeis e suas análises. $\mathrm{O}$ resultado da pesquisa mostra que os contadores valem-se de diversos tipos de instrumentos de controles de gestão com o propósito de auxiliar o processo de gestão, centralizados sobre tudo, nas demonstrações contábeis e suas análises.

Fernandes e Galvão (2016) realizaram um estudo sobre a viabilidade e a relação de custo benefício da controladoria como ferramenta de gestão nas micro e pequenas empresas. Dessa forma o resultado do estudo diz que a escassez de recursos, não é suficiente para melhorar o desempenho empresarial. A falta de conhecimentos técnicos por parte dos gestores torna necessário o auxílio de um profissional especializado para fazer uma análise financeira, econômica e patrimonial mais aprofundada. Isso revela, em geral, a maneira intuitiva que é conduzida a gestão nas MPEs, sem distinguir entre geração de caixa e acumulação de lucro, comprometendo assim, as decisões estratégicas. Embora haja muita resistência por parte das MPEs quanto à adoção da controladoria como ferramenta de gestão, é possível defender sua viabilidade, uma vez que se pode adequá-la à estrutura organizacional, independente do porte da empresa. Pode-se concluir que os benefícios advindos da controladoria excedem os seus custos, pelo menos, a médio e longo prazo. Mesmo quando há escassez de recursos financeiros, as MPEs devem entender esse desembolso como um investimento importante para a empresa. Pois, o retorno poderá ser infinitamente superior, ao proporcionar crescimento e longevidade às empresas.

\section{METODOLOGIA}

O objetivo é identificar como a controladoria pode dar suporte ao processo de geração de informações voltadas à controladoria, em uma entidade sem fins lucrativos. Pode-se dizer que quanto aos seus objetivos trata-se de um estudo descritivo, em razão de expor as características de determinada população ou de determinado fenômeno, podendo estabelecer correlações entre variáveis e definir sua natureza. Não tem compromisso de explicar fenômenos que descreve, embora sirva de base para tal explicação (VERGARA, 2009). Esta classificação se deve ao fato de buscar relacionar as características com os objetivos específicos do estudo, descrevendo o objeto de estudo.

Quanto aos procedimentos classifica-se como estudo de caso e documental. A análise documental, considerando a consulta dos documentos e relatórios disponibilizados pela organização estudada. A pesquisa documental é aquela cujos documentos e/ou matérias ainda não foram devidamente analisados, mas que, de acordo com a questão e objetivos da pesquisa, podem ter valor científico (GIL, 2002).

O estudo de caso em razão aprofundar o objeto de pesquisa, de maneira a permitir seu conhecimento amplo e detalhado. Pode-se conceituar que o estudo de caso é um estudo empírico que investiga um fenômeno atual dentro do seu contexto da realidade, quando as fronteiras entre o fenômeno e o contexto não são claramente definidas e no qual são utilizadas das várias fontes de evidência (CARVALHO, 2010; GIL, 2010).

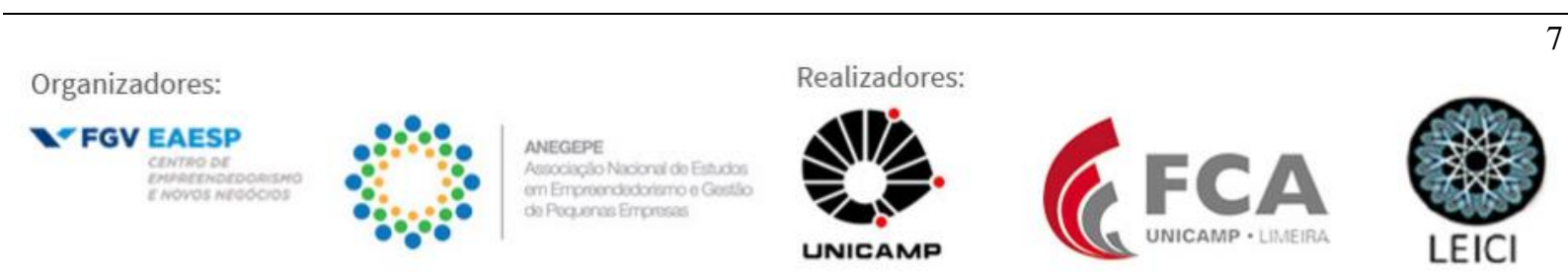


No que se refere a abordagem do problema a pesquisa se caracteriza como qualitativa por não usar métodos estatístico, visando identificar e interpretar situações que carecem de melhorias numa determinada organização, propondo possibilidades para que estas sejam melhoradas, evitadas ou solucionadas (RICHARDSON, 2010). Envolve basicamente a análise de percepções sobre situações pertinentes ao tema.

Em uma pesquisa qualitativa, há uma relação dinâmica entre o mundo real e o sujeito, ou seja, um vínculo indissociável entre o mundo real e a subjetividade do sujeito, não podendo ser traduzidos em números. Na pesquisa o ambiente natural é a fonte direta para a coleta de dados e informações, sendo o pesquisador o instrumento-chave (ZAMBERLAN et al., 2014).

A organização presta serviços, a fim de representar o comércio de bens e de serviços em busca da excelência no setor terciário varejista, visando a sua integração e crescimento através de uma política de desenvolvimento sócio econômico sustentável. Promover a socialização justa nas relações trabalhistas e o desenvolvimento de novas lideranças no setor.

Dessa forma optou-se por fazer um estudo de caso, explorando ao máximo a função controladoria na empresa. A coleta de dados ocorreu diretamente com o gestor da empresa e o contador, a partir do envolvimento destes nas atividades de organização de processos e da estrutura administrativa além de participar ativamente da implantação de mecanismos de acompanhamento e controles do negócio.

Para obtenção dos dados para análise, busca-se empregar como instrumento de pesquisa a entrevista estruturada. Na visão de Marconi e Lakatos (2003), a entrevista é o encontro entre duas pessoas, para que uma delas obtenha dados inerentes a determinado problema, mediante conversação de natureza profissional.

Por entrevista semiestruturada, as mesmas autoras (2003) entendem ser aquela em que o entrevistador segue um roteiro previamente estabelecido; e as perguntas feitas aos indivíduos decorrem das necessidades do entrevistador de buscar informações que viabilizem a resposta da questão investigadas.

A partir do estudo de Machado L., Machado M., Santos (2008), foi aplicado um roteiro de entrevista com os seguintes pontos: na empresa se reconhece a controladoria; relatar a missão da controladoria e a as funções exercidas pelo setor; além desses pontos, indagou-se também a participação da Controladoria no atual processo de gestão da empresa, principalmente na contribuição do melhoramento do sistema de informação gerencial e seu papel na prestação de informações aos agentes de mercado.

\section{ANÁLISE DOS RESULTADOS}

Com o intuito de atender ao objetivo de identificar como a controladoria pode dar suporte ao processo de geração de informações voltadas à controladoria, em uma entidade sem fins lucrativos. Sendo que a partir das entrevistas e indagações junto ao gestor e contador, identificou-se a utilização dos controles de gestão quanto aos instrumentos contábeis gerenciais e demais instrumentos de auxílio à gestão e, por fim, a utilização de sistema de informação para dar suporte aos controles de gestão.

Com relação ao reconhecimento da controladoria, a mesma não seria reconhecida pela sua denominação conforme as referências teóricas aplicadas no estudo, ou
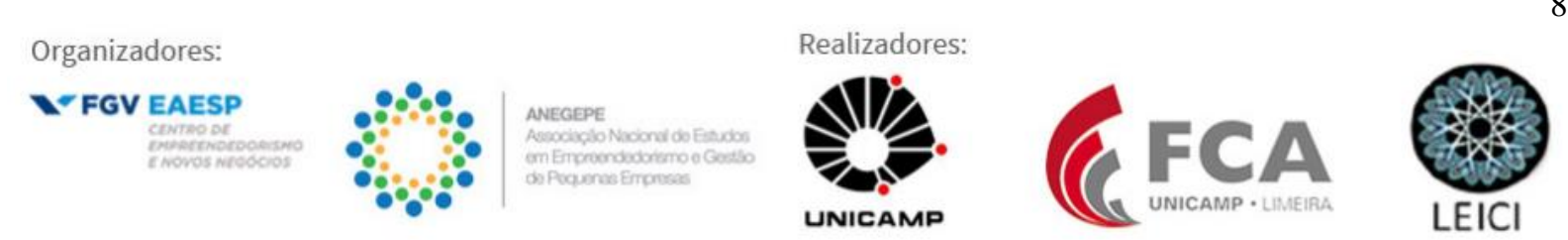
seja, ela é como uma peça fundamental e bem definida que auxilia na aplicação, análise e orientações no processo de gestão da organização. Existe com Concelho Fiscal, composto por três membros, que realizam a maior parte das ações de controle dentro da organização.

A controladoria na empresa tem o papel de controle econômico e financeiro, bem como a geração das informações para a direção da empresa. Onde busca aplicar os preceitos estabelecidos, como a missão e função da controladoria, deixando sempre bem claro, o aproveitamento a e execução desses controles. Separado por setores como a contabilidade, financeiro e RH, os mesmos tem como papel fundamental, o controle e a geração de informação dos controles para a diretoria. Todos os recebimentos e pagamentos passam pelos devidos setores, assim então, separados e alocados na contabilidade. Mensalmente apresentase o balancete de verificação, comparado o orçado com o realizado, dessa forma, trimestralmente o setor da contabilidade realiza reuniões com o conselho fiscal para apresentação dos resultados. As tomadas de decisões são realizadas por meio de relatórios orçamentários, onde depois de analisada a situação econômica e financeira da empresa por meio dos demonstrativos contábeis, o gestor faz sua análise e apontamentos, assim, repassando a diretoria para a execução final.

Além desses pontos, indagou-se também a participação da controladoria no atual processo de gestão da empresa, principalmente na contribuição do melhoramento do sistema de informação gerencial e seu papel na prestação de informações aos agentes de mercado.

A seguir alguns questionamentos que foram colocados ao gestor e a contadora da empresa. Com relação as funções da controladoria e sua aderência aos referenciais teóricos as informações auferidas junto ao gestor e contador da empresa.

Buscou-se inicialmente saber qual o papel do gestor em subsidiar o processo de gestão (planejamento, execução de planos e controles de atividades). O gestor entrevistado (2017) menciona que seu papel é auxiliar na tomada de decisões das ações, tanto da área financeira quanto administrativa. Todos os processos passam pelo gestor para fins de avaliação, para que possa se dar o despacho final. Quando entrevistado o contador (2017) este destaca que sua contribuição em subsidiar a gestão ocorre por meio dos orçamentos e dos relatórios contábeis, onde o processo de gestão é subsidiado pelas informações geradas na contabilidade. A verificação dos controles financeiros (caixa e banco, contas a pagar e a receber) são realizados no setor e conferidos pelo tesoureiro e pela contadora. De acordo então com as referências apresentadas no estudo, um modelo de gestão é a base fundamental para um bom processo de gestão, que servirá como suporte a tomada de decisões e os gestores são peças fundamentais para que esse modelo seja executado e elaborado de acordo com as necessidades e deficiências da organização.

Na sequência foi questionado como realiza-se o apoio a avaliação de desempenho da empesa e com quais instrumentos os gestores atuam. O gestor entrevistado (2017) este relatou que por meio de autorizações do setor contábil, o qual disponibiliza relatórios contábeis para que seja realizada uma análise da situação financeira, contábil e administrativa da entidade. Quando entrevistado o contador (2017) salienta que é através de apresentação dos resultados, relatórios comparativos entre orçado e realizado, análise vertical e horizontal de balanço mensalmente. Dessa forma pode-se observar a aderência da gestão realizada na empresa pelos instrumentos e métodos de avaliação ofertados pela controladoria, afim de estabelecer métodos e caminhos para que as metas e objetivos sejam alcançados.

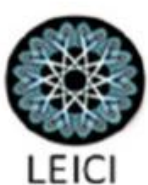


Após indagou-se como é feita a avaliação dos resultados na empresa e qual o papel dos gestores nesta fase. O gestor entrevistado (2017) este informou que na entidade existe um Conselho Fiscal composto por três membros, os quais acompanham o desempenho da empresa por meio de relatórios e repassam as informações ao gestor. Dessa forma o gestor receber estas informações para auxiliarem na tomada de decisões, averiguando se as atividades estão ocorrendo dentro da programação, se os resultados prévios estão dentro do esperado para o projeto, como prazos e custos. Exercendo o controle o gestor, junto com sua equipe, pode identificar se as etapas do projeto estão sendo realizadas conforme planejado. Quando entrevistado o contador (2017) esclarece que enquanto contadora, elaboro apresentação dos resultados, mensalmente para o diretor geral, trimestralmente para o conselho fiscal, e anualmente para toda a diretoria, os resultados são considerados por meio da apresentação dos relatórios contábeis e da análise vertical e horizontal da DRE e do Balanço Patrimonial. De acordo com o referencial apresentado, a controladoria é a área responsável por medir possibilidades e expectativas, elaborando políticas de gestão para a empresa, ou seja, avaliar o desenvolvimento adequado para a organização. Assim gerenciar todo esse processo é tarefa dos gestores, que precisam conhecer tudo acerca da organização. Exercendo o devido controle, averiguando se as atividades estão correndo de acordo com o planejado e executado e então assim, administrar os conflitos e suprir as necessidades da empresa.

Ainda se questionou sobre o sistema de informações, o qual é o caminho pelo qual transitam os eventos econômicos. Dentro do sistema têm-se as funções de registrar, acumular, organizar e finalmente comunicar os resultados as pessoas que precisam dos números. Dessa forma questionou-se o papel que os gestores desenvolvem no melhoramento do sistema de informações da empresa. O gestor entrevistado (2017) menciona que é por meio de um acompanhamento bem adequado, sempre realizando uma análise das informações prestadas, na busca de uma visão ampla da organização. Quando entrevistado o contador (2017) relatou que através da organização dos setores, controles de contas a pagar e receber, controle dos documentos apresentados na contabilização. Tendo por base os referenciais teóricos, os sistemas de informações são um conjunto integrado de informações, que tem por propósito apoiar as operações e funções de gestão de uma empresa, visando facilitar a captação do processo administrativo em todas as suas fases de decisões. Assim o gestor é parte fundamental de todo este processo de análise, afinal é através dele que a empresa consegue acompanhar esse desenvolvimento e visualizar as informações prestadas pelo sistema.

Por fim buscou-se questionar sobre as informações aos agentes de mercado, como e se os gestores auxiliam em algum tipo de trabalho que vise ofertar informações a esses agentes, e ainda, quais seriam os trabalhos desenvolvidos por eles nessa fase. O gestor entrevistado (2017) informou que monitoro o fluxo de informações que tramitam em cada setor, porém não exerço muita interferência com relação aos agentes de mercado. As demais informações e relatórios são elaborados pelo Conselho Fiscal, cujo faz o devido repasse e interferência aos agentes de mercado. Não possuo muito conhecimento, nem mesmo interfiro muito nessa relação com os agentes de mercado. Quando entrevistado o contador (2017) esclarece que as informações geradas pela controladoria são repassadas aos órgãos de interesse, mas a contadora não atua nessa fase, é outro setor.

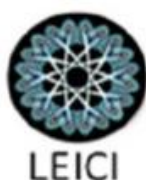


Com relação a análise das funções e atividades da controladoria executadas na organização que foram questionadas ao gestor e contador da entidade, observa-se que o processo de gestão é subsidiado por tais, gerenciando um sistema de informações que permitam projeções de processos econômicos no processo decisório, proporcionando aos gestores informações de desempenho e resultado e ainda de forma auxiliar no monitoramento para a elaboração de orçamentos e sua devida consolidação.

Ainda se indagou a ferramenta de apoio a avaliação de desempenho e resultado da organização, onde demonstrou-se parcialmente executada, para fins de elaboração de relatórios de análise dos gestores, desempenho econômico da empresa e da própria área, não sendo utilizada para análise de desempenho de outras áreas. Sobre o apoio aos resultados, como ferramenta na análise de resultado de produtos e serviços, em orientar o processo de estabelecimento de padrões e ainda, parcialmente na avaliação de serviços prestados pela própria controladoria.

Para finalizar a análise questionou-se ainda com relação a controladoria gerir o sistema de informações, onde observa-se que que a mesma atua de forma a ordenar as informações do sistema para a gestão e padronizando os modelos de decisões. Porém como ferramenta para definir modelos de decisões observa-se parcialmente por apenas um dos gestores. Quando questionado sobre a controladoria atender os agentes de mercado afirmaram que a mesma é utilizada como uma ferramenta, a fim de acompanhar a legislação aplicável a empresa e ainda zelar pelas informações prestadas.

Tendo por base as informações coletadas nas entrevistas com a profissional Contábil e o Gestor, a análise partiu das informações prestadas pelos profissionais e ainda aquelas apresentadas na parte teórica do estudo, que tratavam das funções da Controladoria. Indagouse ainda, algumas questões com relação as funções e atividades da Controladoria executadas na entidade. Verifica-se que boa parte das funções previstas são exercidas na empresa, assim, a entidade não corre riscos e também não está vulnerável a uma má gestão.

A seguir foi apresentado um quadro em que é possível observar as respostas de cada profissional, referente as funções da controladoria. Nesse sentido baseando-se nas informações coletadas na entrevista com os profissionais da controladoria da empresa (contador e gestor), percebe-se ser a organização estudada bem organizada a qual tem utilizado a controladoria para a tomada de decisão, o que não tem sido efetivamente uma realidade vivida em empresas onde a Controladoria existe. A pesquisa de Machado L., Machado M., Santos (2008) indicou que boa parte das funções da controladoria não são exercidas plenamente nas organizações.

A análise das funções da controladoria partiu das informações prestadas pelos profissionais entrevistados e dos tópicos apresentados na parte teórica do estudo, que tratavam das funções da controladoria. Observa-se que na organização estudada segundo a visão do contador foram identificadas 12 funções da controladoria e na visão do gestor foram encontradas 14 funções de um universo de 15 atividades previstas no estudo de Machado L., Machado M., Santos (2008). Porém, as atividades exercidas pelo profissional não guardam total aderência com os ensinamentos dos autores.

É oportuno destacar que os preceitos de controladoria foram interpretados à luz da gestão empresarial (FERNANDES; GALVÃO, 2016) e da gestão econômica (CATELLI et al., 2001). Isso decorre do fato de que na visão dos entrevistados não é função da

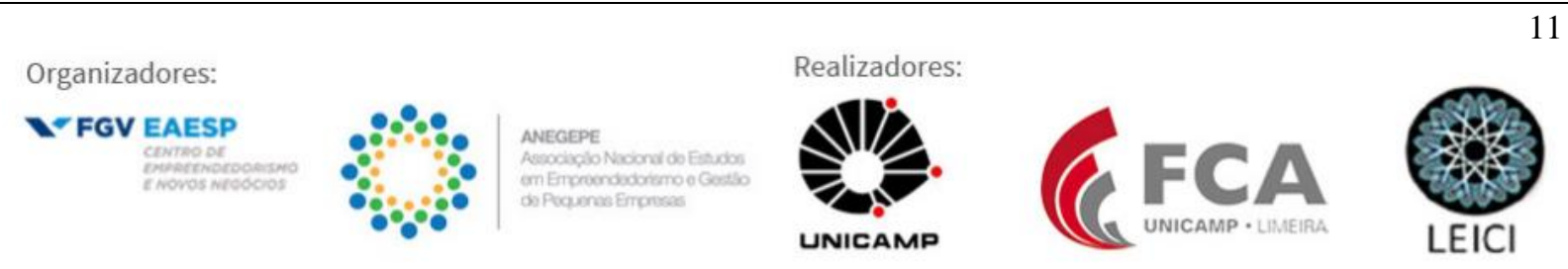


controladoria somente três dos 15 atributos observados: elaborar relatório de análise de desempenho das áreas; avaliar os serviços prestados pela própria controladoria; e definir modelos de decisões, os quais tratam-se de abordagem bem voltadas para a gestão empresarial e econômica.

Quadro 1 - Análise da função Controladoria

\begin{tabular}{|c|c|c|c|c|}
\hline \multirow[b]{2}{*}{ Funções / atividades da Controladoria } & \multicolumn{2}{|c|}{$\begin{array}{l}\text { Executadas na entidade } \\
\text { pesquisada? Gestor }\end{array}$} & \multicolumn{2}{|c|}{$\begin{array}{l}\text { Executadas na entidade } \\
\text { pesquisada? Contador }\end{array}$} \\
\hline & SIM & $N \tilde{A} O$ & SIM & $N \tilde{A} O$ \\
\hline \multicolumn{5}{|l|}{ 1- Subsidiar o processo de gestão } \\
\hline $\begin{array}{l}\text { a) Gerenciar um sistema de informações que permitam } \\
\text { projeções de processos econômicos no processo } \\
\text { decisório. }\end{array}$ & $X$ & & $X$ & \\
\hline $\begin{array}{l}\text { b) Proporcionar aos gestores informações de } \\
\text { desempenho do resultado econômico. }\end{array}$ & $\mathrm{X}$ & & $\mathrm{X}$ & \\
\hline $\begin{array}{l}\text { c) Monitorar a elaboração de orçamentos e sua } \\
\text { consolidação na empresa. }\end{array}$ & $\mathrm{X}$ & & $\mathrm{X}$ & \\
\hline \multicolumn{5}{|l|}{2 - Apoiar a avaliação de desempenho } \\
\hline $\begin{array}{l}\text { a) Elaborar relatório de análise de desempenho das } \\
\text { áreas. }\end{array}$ & & $X$ & & $\mathrm{X}$ \\
\hline b) Elaborar relatório de análise dos gestores. & $\mathrm{X}$ & & $\mathrm{X}$ & \\
\hline $\begin{array}{l}\text { c) Elaborar relatório de análise de desempenho } \\
\text { econômico da empresa. }\end{array}$ & $\mathrm{X}$ & & $\mathrm{X}$ & \\
\hline d) Elaborar relatório de desempenho da própria área. & $\mathrm{X}$ & & $\mathrm{X}$ & \\
\hline \multicolumn{5}{|l|}{ 3- Apoiar a avaliação de resultado } \\
\hline a) Análise de resultado de produtos e serviços. & $\mathrm{X}$ & & $\mathrm{X}$ & \\
\hline b) Orientar o processo de estabelecimento de padrões. & $\mathrm{X}$ & & $\mathrm{X}$ & \\
\hline $\begin{array}{l}\text { c) Avaliar os serviços prestados pela própria } \\
\text { Controladoria. }\end{array}$ & $\mathrm{X}$ & & & $X$ \\
\hline \multicolumn{5}{|l|}{4 - Gerir o Sistema de Informações - SI } \\
\hline a) Ordenar as informações do SI para a gestão. & $\mathrm{X}$ & & $\mathrm{X}$ & \\
\hline b) Definir modelos de decisões. & $\mathrm{X}$ & & & $\mathrm{X}$ \\
\hline c) Padronizar modelos de informação. & $\mathrm{X}$ & & $\mathrm{X}$ & \\
\hline \multicolumn{5}{|l|}{5 - Atender aos agentes de mercado } \\
\hline a) Acompanhar nova legislação aplicável à empresa. & $\mathrm{X}$ & & $\mathrm{X}$ & \\
\hline b) Zelar por informações prestadas. & $\mathrm{X}$ & & $\mathrm{X}$ & \\
\hline
\end{tabular}

Tais constatações são merecem destaque, visto que as funções da controladoria observada na pesquisa cabem bem num ambiente que não trabalha exclusivamente com a gestão econômica mas guardam ligação com o processo de gestão como um todo, independente do modelo adotado, garantindo que as decisões dos gestores contribuam para otimizar o desempenho da organização. Dessa forma a controladoria está intrinsecamente ligada às atividades de elaboração, controle e avaliação de desempenho que fazem parte do escopo da gestão como um todo (FERNANDES; GALVÃO, 2016).

Com base na fundamentação teórica e após o levantamento e a análise das operações e dos controles existentes na organização, apresenta-se, a seguir, uma proposta de configuração da controladoria para dar suporte ao seu processo de gestão e controle. A controladoria apresenta-se como órgão responsável pelo desenvolvimento e implantação de um sistema de

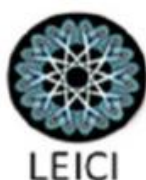


informações gerenciais, integrando as atividades operacionais e gerando controles e relatórios contábeis-gerenciais para dar suporte ao processo decisório.

Nesse sentido, apresenta-se uma proposta de modelo organizacional da controladoria, destacando a responsabilidade, autonomia administrativa, conhecimento da gestão organizacional e um maior controle dos indicadores da empresa. Assim, os objetivos do órgão controladoria devem estar voltados a:

- Observação do desempenho de maneira sistemática e coerente com os objetivos, metas e padrões estabelecidos;

- Comparação do desempenho real com o esperado;

- Comunicação do desempenho com as alternativas de ação em decorrência de variações relevantes;

- Atender as necessidades da alta administração proporcionando um conhecimento mais amplo por todos os responsáveis nas tomadas de decisões;

- Efetuar de forma com mais frequência avaliação dos resultados, comparando o realizado com o orçado;

- Implementar modelos de decisões;

Nota-se que o estudo procurou demonstrar a relevância da controladoria no processo de gestão das organizações, como um órgão administrativo definido na estrutura organizacional, com o propósito de oferecer o devido apoio à consecução dos objetivos institucionais. Dessa forma os conceitos de gestão e controladoria foram abordados com base os seus princípios, missão, função e objetivo, os quais são peças fundamentais para o processo de tomada de decisões e de eficácia organizacional.

Como na maioria das empresas, em suas estruturas organizacionais ocorre o processo de departamentalização, ou seja, difusão da empresa em unidades em qual cada um possui responsabilidades especificas, mas que se relacionam às outras, assim alcançando objetivo comum da empresa. Desta forma facilita o fluxo de informações, e conforme o modelo de gestão da empresa está incluída em sua estrutura organizacional a controladoria, que em suas funções e missões abrange desde a fase de planejamento até a execução e controle das atividades empresariais.

O órgão administrativo controladoria tem por finalidade garantir informações adequadas ao processo decisório, colaborando com os gestores na busca da eficácia gerencial. A controladoria em muitas empresas é considerada como um dos principais órgãos administrativos, pois repassa aos gestores as informações dos recursos disponíveis para o processo de produção e também a análise do desempenho das operações em um todo para que se chegue ao objetivo final com eficiência e a eficácia.

Comprovando que a missão da controladoria é de otimizar os resultados econômicos e fornecer suporte informacional em todas as etapas do processo de gestão, com intenção de assegurar os interesses da empresa, pois neste campo dos negócios, a organização tem que ter funções otimizadas e que estejam acompanhando e avaliando os negócios e se estão compatíveis com os que inicialmente planejado. Principalmente pelo o fato de que neste cenário dos negócios ocorre as competividades das empresas, a intensa instabilidade e os desenvolvimentos tecnológicos, as influências governamentais e o comportamento dos consumidores e fornecedores, são alguns fatores que influenciam a situação empresarial, ameaçando ou oferecendo oportunidade à sobrevivência dela.
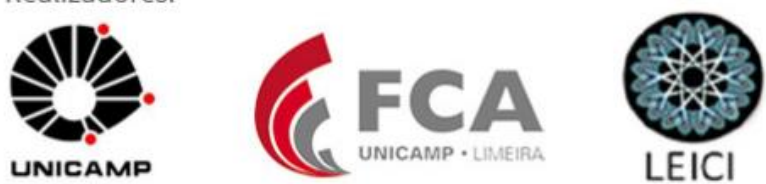
Neste contexto, é valido afirmar que a atual organização se encontra devidamente preparada, apenas necessitando de alguns ajustes que tragam mais melhorias a estrutura e desenvolvimento da empresa. Assim, a responsabilidade de um melhor gerenciamento da empresa é um fator determinante para o seu crescimento, pois se cria a necessidade de um sistema que identifique quais os padrões que deverão ser mantidos e quais os que necessitarão serem mudados para que haja a eficiência e a eficácia da organização dentro de um resultado econômico satisfatório.

\section{CONCLUSÃO}

A investigação teve por finalidade verificar como a controladoria era executada dentro da organização e se a mesma estaria configurada a fim de dar o devido suporte a gestão organizacional. Assim subsidiando os gestores com relatórios contábeis-gerenciais, para acompanhamento e elaboração do planejamento e do controle operacional.

Neste contexto o alcance do objetivo teve como finalidade responder à questão de pesquisa que foi saber como a controladoria pode dar suporte ao processo de geração de informações voltadas à controladoria, em uma entidade sem fins lucrativos. Nesse sentido os resultados indicam que a Controladoria dá o devido suporte ao processo de geração de informações, a fim de ser um instrumento de gestão, contribuindo com o planejamento, execução e controle de suas atividades, auxiliando na tomada de decisões. Todavia, apenas o conhecimento dos instrumentos da controladoria, não é suficiente, é preciso que eles sejam aprimorados e conhecidos pelos principais gestores dentro da organização para produzir uma gestão eficiente e eficaz. De forma geral a organização possui instrumentos de gestão que podem levar a otimização dos resultados, apresentando uma boa gestão com gestores capacitados, gerando informações que possam ajudar no processo de tomada de decisões.

Destaca-se a importância de utilizar a controladoria como ferramenta estratégica de gestão através de alguns ajustes no planejamento estratégico. Essa ferramenta vem contribuir de forma eficaz com a gestão das pequenas empresas, uma vez que sua função é estabelecer as metas e objetivos para delinear o rumo da entidade, identificando os pontos fortes e fracos, as ameaças e oportunidades, ou seja, as variáveis para se atingir tais objetivos.

Desta forma a organização precisa de gestores que possuam uma ampla visão, que enxergue as dificuldades, e que proponha soluções, assim a controladoria vem como base para esta configuração de organização. Um modelo de gestão, definido ou não, expõe as diretrizes pelas quais se pretende gerir os negócios da entidade, e que pela controladoria o modelo de gestão ideal, é que se tenha um processo de gestão, que prossegue desde o planejamento, execução e controle, e que assim direcione para as tomadas de decisões e resulte em um resultado satisfatório no geral. Assim fica claro que a controladoria, como um órgão administrativo, é tornar a organização viável a todos que diretamente ou indiretamente está relacionada a ela, coordenando o processo de gestão empresarial com objetivo à eficácia.

\section{REFERENCIAS}


ALVES, Marleide Ferreira; BOMFIM, Pedro Henrique Monteiro; SOUZA, Renata Freire de. A importância dos sistemas de informações contábeis aos seus usuários. Artigo. Org. Soc., Iturama (MG). v. 5, n. 3.12 p. 2016.

BAIRRO, Darliene Rodrigues de. Sistema de Informação Contábil como Ferramenta para Tomada de Decisões. 2008. 45 p. Trabalho de Conclusão de Curso Universidade Tecnológica Federal do Paraná Pato Branco/PR, 2008. Disponível em:

$<$ http://bibliotecadigital.pb.utfpr.edu.br/bibliotecadigital/index.php/ecap/article/viewA rticle/466> Acesso em: 02 mar. 2017.

BASSO, Irani Paulo; BRIZOLLA, Maria Margarete Baccin; FILIPIN, Roselaine. Contabilidade: geral básica. 5.ed. rev. Ijuí: Ed.UNIJUI, 2017. 476 p.

BERGONSO, Verena Rodrigues; SILVA, Daiany Suellen. Controladoria como Ferramenta para Gestão do Sistema de Produção: Nical Produtos Infantis LTDA-ME. Lins/SP. 2010. 105 p. Trabalho de Conclusão de Curso - Centro Universitário Católico Salesiano Auxilium, Lins/SP, 2010. Disponível em: < http://www.salesianolins.br/universitaria/avaliacao/no2 /artigo8.doc> Acesso em: 16 abr. 2017.

BEUREN, Ilse Maria; MULER, Elsa Terezinha Cordeiro. Estrutura Formal e Práticas a Controladoria em Empresas Familiares Brasileiras. Gestão \& Regionalidade. v. 26, n. 76, enero-abril, p. 105 - 120, 2010. Disponível em: <http://search.proquest.com/openview/ e06b2614c634c2bba0348fc78d30dae3/1?pq-origsite $=$ gscholar $\& \mathrm{cbl}=2035835>$ Acesso em: 06 mar. 2017.

BEZERRA, Josecleia Oliveira; LEMOS, Uillams Moraes. A Controladoria como Ferramenta Estratégica na melhoria da gestão de Pequenas Empresas. Revista Eletrônica da Faculdade José Augusto Vieira. v.6. 21 p. Edição Especial. Março 2013.

BONIATI, Jéssica Schreiber; BRIZOLLA, Maria Margarete Baccin; FILIPIN, Roselaine; STEIMBRENNER, Anelia Franceli;VIEIRA, Euselia Paveglio; BASSO, Lauri. O processo orçamentário sob a ótica contingencial em uma Instituição de Ensino Superior do estado do RS. In: XV COLÓQUIO INTERNACIONAL DE GENTÃO UNIVERSITARIA, 2015. Anais..., Mar Del Plata (AR), 2015.

CARVALHO, Maria Cecília M. de. Construindo o saber: Metodologia Científica Fundamentos e Técnicas. 23. ed. Campinas, SP: Papirus, 2010. 251 p.

CATELLI, Armando et al. Controladoria: uma abordagem da gestão econômicaGECON. São Paulo: Atlas, 2001. 999 p.

CREPALDI, Rosângela. O uso de Controles de Gestão: Um estudo com os Contadores Filiados no Sindicato dos Contabilistas de Criciúma. Monografia - 
Universidade do Extremo Sul Catarinense, Criciúma/SC, 2015. Disponível em: < http://dspace.unesc.net/handle/1/4010> Acesso em: 06 mar. 2017.

DIAS, Bibiana Borges. O papel da controladoria no suporte ao processo de geração de informações voltadas ao controle de gestão operacional: em empresa prestadora de serviços de hemodinâmica. Dissertação - Universidade Federal de Santa

Catarina, Florianópolis, 2002. Disponível em: https://repositorio.ufsc.br/handle/123456789/83432>. Acesso em: 22 mar. 2017.

FERNANDES, Ailton Matos; GALVÃO, Paulo Roberto. A Controladoria como ferramenta de gestão nas micro e pequenas empresas: um estudo da viabilidade e da relação custo benefício. Revista de Tecnologia Aplicada, v. 5 n. 1, p. 3-16. Jan-Abril 2016. Disponível em: < http://www.faccamp.br/ojs/index.php/RTA/article/view/904> Acesso em: 09 mar. 2017.

FISCH, Silvio; MOSIMANN, Clara Pellegrinello. Controladoria: seu papel na administração de empresas. 2. ed. - São Paulo: Atlas, 1999. 137 p. 2002. 176 p.

GIL, Antônio Carlos. Como elaborar projetos de pesquisa. 4. Ed. São Paulo: Atlas

GIL, Antônio Carlos. Métodos e Técnicas de Pesquisa Social. 6. ed. São Paulo: Atlas, 2010. 200 p.

LAKATOS, Eva M.; MARCONI, Marina de A. Técnicas de Pesquisa: planejamento e execução de pesquisas, amostragem e técnicas de pesquisa, elaboração, análise e interpretação de dados. 5. Ed. São Paulo: Atlas, 2002. 231 p.

LUNKES, Rogério. João; SCHNORRENBERGER, Dartci; GASPARETTO, Valdirene; VICENTE, Ernesto Fernando Rodrigues. Considerações sobre as funções da controladoria nos Estados Unidos, Alemanha e Brasil. Revista universo contábil, ISSN 1809-3337, FURB, Blumenau, v. 5, n.4, p. 63-75, out./dez.,

2009.

MACHADO, Lúcio de Souza; MACHADO, Michele Rilany Rodrigues; SANTOS, Eduardo José dos. Atuação da Controladoria em uma Empresa de Médio Porte: um Estudo de Caso. Revista Contemporânea de Contabilidade, v. 1, n. 10, p. 53-67. Jul-Dez 2008. Disponível em: 〈https://periodicos.ufsc.br/index.php/contabilidade/article/view/4872 > Acesso em: 06 mar. 2017.

NASCIMENTO, Auster Moreira; REGINATO, Luciane. Controladoria: instrumento de apoio ao processo decisório. São Paulo: Atlas, 2009. 319 p. 
OLIVEIRA, Antônio Benedito Silva. Controladoria: fundamentos do controle empresarial. São Paulo: Saraiva, 2009. 346 p.

PADOVEZE, Clovis Luis. Controladoria estratégica e operacional: conceitos, estrutura e aplicação / 2. ed., rev. e atual. São Paulo: Cengage Learning, 2009. 493 p.

POLITELO, Leandro; GUSE, Jaqueline Carla; LEITE, Maurício; SILVA, Tarcisio Pedro; DORR, Adreia Cristina. Uma análise em organização sob a ótica da Controladoria Empresarial. Desafio online, v. 2, n. 1, p. 487-504, jan/abr 2014.

RICHARDSON, Roberto Jarry et al. Pesquisa social: métodos e técnicas. 3. ed. São Paulo: Atlas, 2010. 334 p.

Sebrae. Brasília, out. 2016. Disponível em: https://www.sebrae.com.br/Sebrae/Portal\%20Sebrae/ Anexos/sobrevivencia-das-empresasno-brasil-relatorio-2016.pdf> Acesso em: 06 mar. 2017.

VERGARA, Sylvia Constant, Projetos e relatórios de pesquisa em Administração. 2. ed. São Paulo: Atlas, 2009. 248 p.

ZAMBERlan, Luciano et al. Pesquisa em Ciências Sociais Aplicadas. Ijuí: Ed. Unijuí, 2014. 208 p. 